\title{
LA CATEDRAL, SEDE DEL OBISPO EN LA EDAD MEDIA
}

\author{
POR \\ ILUMINADO SANZ SANCHO \\ Profesor Titular de la Universidad Autónoma de Madrid
}

Están apareciendo nuevos estudios sobre las iglesias catedrales en la Edad Media, en sus diferentes aspectos. Se celebran seminarios y congresos sobre diversos asuntos de la gran riqueza temática e histórica que confluye en las catedrales medievales ${ }^{1}$. Todo esto enriquece en su variedad el tema, todavía hoy día tan grandioso y encomiable, como símbolo de un largo período de nuestra historia más impactante.

También nosotros participamos de esta corriente de estudio. Queremos, pues, proponer un esquema de comprensión en torno a la figura e institución capital del obispo, válido desde muchos puntos de vista y que tenga la virtualidad de unificar y hacer comprensibles los diferentes aspectos a estudiar en las catedrales.

En efecto, la catedral es la iglesia de la cátedra (en griego kathédra) del obispo de la ciudad y de su territorio diocesano, es decir la sede (en latín sedis) donde se sienta el obispo para adoctrinar como maestro a los oyentes en general y particularmente a los catecúmenos y a los ya cristianos.

\section{INSTITUCIÓN Y DESARROLLO DEL EPISCOPADO EN LA ANTIGÜEDAD.}

\section{El episcopado en los siglos I-III.}

Las funciones del obispo en cada diócesis e iglesia catedral se han desarrollado y han evolucionado en el fondo y en la forma desde la primera aparición de su figura e institución en las cartas de San Pablo, donde se habla del obispo (en griego epískopos), que significa "guardián, protector, vigilante, inspector".

"Y así los puso Dios en la Iglesia, primeramente como apóstoles; en segundo lugar como profetas; en tercer lugar como maestros; luego el poder de los milagros; luego el don de las curaciones, de asistencia, de gobierno, diversidad de lenguas". (I Cor. 12,28).

"Es, pues, necesario que el obispo sea irreprensible, casado una sola vez, sobrio, sensato, educado, hospitalario, apto para enseñar, ni bebedor ni

* Este artículo contiene sustancialmente nuestra conferencia titulada "La catedral, sede del obispo", pronunciada en la Facultad de Humanidades de Toledo, IV Seminarios de Humanidades, Ciclo de otoño 2008: "El universo de las catedrales en el Medievo", el día 3 de diciembre de 2008.

${ }_{1}^{1}$ Precisamente el $n^{\circ} 1$ de la nueva revista Lope de Barrientos. Seminario de Cultura, Cuenca (España), ISSN: 1888-9530, lleva por título y dedicación temática: "Las Catedrales Españolas. Fuente de Cultura. Historia y Documentación". Según nuestras noticias, también el n 2 se dedicará a semejante temática. 
violento, sino moderado, enemigo de pendencias, desprendido del dinero, que gobierne bien su propia casa y mantenga sumisos a sus hijos con toda dignidad; pues si alguno no es capaz de gobernar su propia casa ¿cómo podrá cuidar de la Iglesia de Dios? Que no sea neófito, no sea que, llevado por la soberbia, caiga en la misma condenación del Diablo. Es necesario también que tenga buena fama entre los de fuera, para que no caiga en descrédito y en las redes del Diablo" (I Tim. 3, 2-7).

En estas dos citas neotestamentarias, escogidas entre varias, el obispo aparece junto a otros cargos y servidores de la Iglesia primitiva, aunque en las llamadas cartas pastorales, atribuidas a San Pablo, su figura ya había alcanzado madurez y mayor importancia, a medida que se iba pasando de una Iglesia carismática y apostólico-misionera o itinerante a una Iglesia de comunidades locales más numerosas y necesitadas de instituciones.

Hasta mediados del siglo II la Iglesia ha ido asumiendo instituciones y figuras provenientes tanto del judaísmo como de la sociedad greco-romana. Así, las iglesias locales solían configurarse según varios modelos de gobierno: uno más colegial, al estilo judío del Sanedrín, con un colegio sacerdotal o de ancianos encabezado por el sumo sacerdote, pero que actúa colegiadamente, y otro de tipo más personal y patriarcal. Ambos modelos pervivieron un tiempo, aunque con diferencias en las distintas iglesias, como las de Antioquía y sobre todo Alejandría. A comienzos del siglo III todavía en Roma se mantenía ya algo desdibujado el modelo colegial del presbiterio presidido por un obispo elegido por este colegio.

Acabó imponiéndose la figura del obispo como fuente y cabeza de la iglesia local en todos los campos, desde la administración sacramental, ya que poseía el sumo sacerdocio, hasta la administración económica de la comunidad, pasando por la vigilancia de la fe y de la predicación, siguiendo por la observancia de las normas disciplinares, aprobadas en los concilios provinciales, regionales y generales. Asumió, por último, el papel de juez árbitro entre los cristianos. Se llega a así a un episcopado monárquico: un solo obispo en cada ciudad y en su territorio.

Mientras las comunidades cristianas fueron poco numerosas y poco extensas en el mundo urbano, valía este esquema. Bastaba la ayuda de un clero que se iba especializando y oficializando y cooperaba con el obispo en cada ciudad, donde sólo había una iglesia propiamente dicha, aunque podían coexistir oratorios, martiria e iglesias de cementerios y mausoleos, que en ciudades grandes, como Roma, se extendieron y acabaron por tener servicio de un clero enviado por el obispo.

Algo semejante pasó en las iglesias rurales, que también debían ser atendidas por el obispo de la ciudad y de su territorio, mediante clérigos delegados episcopales, que mantenían el culto, la acción caritativa de la Iglesia y la recepción y asignación de rentas para los servidores de estas iglesias.

\section{Las funciones eclesiales y asunción del papel socio-político en los siglos IV-VIII.}

Además de esta evolución institucional de la Iglesia en la Antigüedad, hay que tener en cuenta dos fenómenos convergentes, de gran influencia en la posteridad: la extracción social de los obispos y la delegación de funciones jurisdiccionales del imperio romano en ellos. Los dos fenómenos se potencian mutuamente y aumentan la importancia intraeclesial_del episcopado, al proyectar su figura sobre el ámbito sociopolítico. 
La imagen del obispo en las cartas pastorales neotestamentarias viene dibujada como la de un paterfamilias greco-romano, con una preparación religiosa, moral y cultural a la altura de sus funciones directivas y de intermediación y arbitraje en los conflictos entre cristianos. Sobre todo, después de la destrucción definitiva de Jerusalén por el emperador romano Adriano en los años 132-135, el cristianismo se vierte totalmente hacia la cultura greco-romana y abandona en la práctica sus raíces judías, no así raíces veterotestamentarias interpretadas por la traducción de la Septuaginta y en el Nuevo Testamento. Resulta por tanto, necesario reclutar a sus dirigentes entre los miembros mejor formados cultural y políticamente.

Estos solían ser los curiales de las ciudades. De entre ellos sale desde mediados del siglo II la mayoría del clero y sobre todo de los presbíteros y diáconos. También de entre ellos y de otros miembros de la clase ecuestre y aún de la clase senatorial se nombrarán los obispos, pero todavía en el siglo III se dio el caso del papa Calixto I (217-222), que había sido esclavo.

Siendo ya los obispos figuras importantes y significadas de las ciudades del imperio romano a comienzos del siglo IV, el emperador Constantino el Grande acabó creando la episcopalis audiencia, audiencia episcopal o tribunal eclesiástico del obispo por sendas constituciones de los años 318 y 333. La hasta entonces meritoria instancia arbitral del obispo se transforma en tribunal civil competente para numerosos casos no exclusivamente eclesiales, pudiendo incluso intervenir en causas ya iniciadas ante un tribunal civil.

Estas competencias fueron suprimidas y vueltas a conceder por sucesivos emperadores en los siglos IV y $\mathrm{V}$, mientras la figura del obispo como juez y defensor de la ciudad se consolidó más allá de los límites estrictos de la iglesia, adquiriendo también un papel político y de vigilancia de los poderes públicos, que será bien advertido por las ciudades mismas cuando se produzcan las sucesivas invasiones de los pueblos germánicos en el Imperio.

Finalmente, la opción de la Iglesia de inculturarse en el mundo greco-romano, aceptando la pedagogía clásica, aunque bautizada, y no recluyéndose en escuelas especiales, como lo fueron las escuelas rabínicas judías, hizo que los obispos poseyeran una cultura al nivel de los más conspicuos intelectuales paganos del momento, como lo demuestran los apologetas, las querellas doctrinales y queda recogido en las obras de los Padres de la Iglesia...

Paralelamente desde el inicial culto a los mártires, se desarrolló también el de los santos confesores, monjes y obispos, cuyas reliquias enriquecieron santuarios, criptas y altares. Los obispos en general se beneficiaron de este auge de lugares sagrados y de las consiguientes peregrinaciones, pues no sólo poseían las reliquias, sino que también establecían la proclamación, la liturgia y el culto de los santos, así como la recepción de limosnas. Todo esto redundaba en el prestigio episcopal.

La respuesta arquitectónica a esta evolución socio-religiosa fue que en los siglos V-VIII, especialmente, aparecieron los conjuntos catedralicios, donde se concentraban el obispo y el clero y demás oficios eclesiásticos de la ciudad. Estos conjuntos arquitectónicos habían sucedido a las "domus ecclesiae", o casas particulares, donde se celebraban las eucaristías y reuniones comunitarias, desaparecidas ya o reconvertidas en basílicas e iglesias. Siguió prosperando, sin embargo, la construcción de oratorios y capillas intra y extra muros de la ciudad, obra e iniciativa de grandes propietarios o de fundaciones. 
Estas agrupaciones urbanísticas solían contar con una o dos iglesias, verdaderos templos, con baptisterio, capillas, casa del obispo y de sus servidores, patios interiores, techados exteriores, pórticos y dependencias para albergar a los peregrinos, cuidar a los enfermos y asistir a los pobres. Todas estas funciones se remontaban a los tiempos paulinos, en el siglo I. Ahora tenían mayor auge.

Al principio solían instalarse estos conjuntos de edificios a las afueras de las ciudades, pues hasta mediados del siglo VI no se procedió de modo más o menos generalizado a reocupar por instituciones cristianas los céntricos espacios urbanos antiguos como foros, basílicas, mausoleos y templos paganos. Pero en uno y otro caso, las construcciones y conjuntos más o menos amplios y más o menos próximos o dispersos, acabaron por convertirse en el corazón de la ciudad, de la ciudad antigua o de la ciudad apenas esbozada y que tendrá su desarrollo en la Edad Media. Eso no quiere decir que estuvieran en el centro mismo del trazado urbano.

3. Variaciones de las funciones episcopales en los siglos IX-X con las figuras del obispo-monje y del obispo mentor real.

La retracción general de Occidente en los siglos VIII-X, particularmente su ruralización y decadencia de las antiguas ciudades, se ve acompañada de una iglesia igualmente rural y de gran presencia monástica, pues los antiguos monasterios urbanos también se han ruralizado en gran medida. Si la cultura casi desapareció de las ciudades o al menos se redujo mucho, también ésta se cobijó en las grandes instituciones monásticas, las únicas con posibilidades económicas y humanas para mantener los instrumentos de la cultura y de su transmisión en sus escuelas monacales.

Es evidente que sus efectos se reflejarán en el incremento del número de obispos elegidos entre los monjes. Eso significará que el clero que ayuda al obispo y demás servidores se conformarán a los ideales monásticos. Por eso, en adelante el modelo arquitectónico no será el conjunto de edificios catedralicios, sino la gran iglesia monástica y eventualmente su claustro anejo, que evolucionará en las épocas románica y gótica. Lo cual no es óbice para que destaquen ocasionalmente construcciones religiosas particulares, como las capillas y los mausoleos de reyes y emperadores.

Otra consecuencia fue la adopción, con ciertas interpretaciones y modificaciones, de la regla benedictina y de otras reglas monásticas para la vida comunitaria del clero catedralicio, ayudante del obispo, como en el caso de $\mathrm{S}$. Crodegango de Metz y de otros grandes reformadores de la época carolingia. Por otra parte, al estilo de la capilla imperial de Aquisgrán, aparecerán instituciones nuevas, como las capillas reales y las colegiatas, donde se formaban los clérigos reales y futuros obispos, que se suman a las ya mencionadas de los monasterios.

$\mathrm{Si}$ las funciones episcopales seguían siendo las mismas, su forma de expresarse varió, tomando mayor fuerza algunas de ellas y cambiando en otro sentido otras. La función litúrgica y sacramental se incrementó tanto, que absorbió casi completamente la función catequética y acabó por delimitar la diferenciación entre el clero y el pueblo, que ya se había iniciado en la época anterior. Igualmente se desarrolló la Liturgia de las Horas, típicamente monacal, hasta implantarse en el clero diocesano y particularmente en el catedralicio y siendo los mismos cristianos obligados a la asistencia a las Vísperas y la Hora Menor, generalmente Tercia o Sexta, previa a la celebración de la Misa mayor dominical. 
La debilidad de las iglesias episcopales urbanas, y a veces la inexistencia de las mismas en países de reciente cristianización, frente a los grandes monasterios y fundaciones de protección papal, real o señorial, repercutió también en la función disciplinaria y jurisdiccional de los obispos y de sus tribunales. La autoridad episcopal a duras penas hacía sentir su presencia en las áreas rurales alejadas de la ciudad y puestas al cuidado de un representante del obispo, comúnmente llamado arcipreste, arcediano o deán.

La predicación, la formación de los cristianos y del futuro clero y el escaso desarrollo cultural manifiesto en los sucesivos "renacimientos" carolingio, otoniano, alfonsino, de Alfonso III de Asturias... en estos siglos son eminentemente monásticos y obedecen primordialmente a los problemas e intereses rurales y monacales. Por lo demás, la función socio-política de los obispos se mantiene en este período, tan distinto del anterior, gracias a sus relaciones con la monarquía, especialmente a través de las capillas reales y al monopolio de la cultura y del pensamiento político en manos de la Iglesia.

\section{LA PROMOCIÓN DEL OBISPO URBANO.}

A lo largo del siglo $\mathrm{XI}$ se inicia en Occidente un renacimiento de las ciudades, acompañado, entre otros aspectos propios de la renovación religiosa y de la llamada reforma gregoriana, de la recuperación de la figura del obispo urbano. Este debe responder en lo religioso a las necesidades nuevas de unas poblaciones ciudadanas, que no pueden ser atendidas por el tradicional monacato y sus ideales de reclusión y de alejamiento del mundo.

Ahora bien, no sólo renacen las ciudades, sino que también se inicia una etapa expansiva en general incluso en el mundo rural de Occidente. A todo esto y los nuevos problemas humanos, culturales y religiosos ha de responder una iglesia nueva, reconstituida a partir de los grandes principios de la llamada reforma gregoriana.

Nos interesa sólo retener que todas las reformas estructurales y las posibilidades de la Iglesia pasan por la recuperación de la figura y de la institución del obispo, definitivamente puesta en el centro de la Iglesia y potenciada cada vez más frente a otras figuras beneméritas del pasado, como los abades de los grandes monasterios. Durante siglos seguirán, no obstante, conviviendo esta y otras instituciones monacales y de nuevas fundaciones conventuales fuera de la jurisdicción episcopal, pues gozaban de exención pontificia.

Puesto que entonces también se inicia la época dorada del Derecho Canónico, podemos tomar del mismo el esquema de las funciones intraeclesiales del obispo definidas como los tres poderes episcopales clásicos: poder de orden, de magisterio y de jurisdicción, que ahora se clarifican y estructuran hasta configurar el esquema de la Iglesia a finales de la Edad Media.

El poder de orden procede del sumo sacerdocio del que está investido el obispo, pues posee el grado máximo del sacramento del Orden Sacerdotal. Eso le faculta para administrar todos y cada uno de los siete sacramentos y de los denominados sacramentales. Ordena la liturgia y los ritos, las festividades religiosas, la consagración de iglesias, de altares y de objetos litúrgicos.

El obispo puede, pues, delegar o facultar en otros sacerdotes, ordenados de presbíteros, de diáconos o de órdenes menores la administración de los sacramentos y la ejecución de las ceremonias litúrgicas. Del mismo modo, también 
puede retener o condicionar la administración de ciertos sacramentos y celebraciones litúrgicas, como vigilias o enterramientos.

Así, de forma general, sólo los obispos podían administrar cualquier orden sagrada en el sacramento del Orden Sacerdotal o el sacramento de la Confirmación, así como conferir la tonsura clerical o la imposición de hábitos y la aceptación en el cargo de abades y priores. En el sacramento de la Penitencia, los obispos se reservaban el perdón de ciertos pecados graves y públicos, que se solían perdonar mediante algún delegado o penitenciario especial y siguiendo determinadas pautas y exigencias de arrepentimiento. Lo mismo cabe decir de la aplicación de la excomunión y del entredicho.

Gracias a la delegación de funciones sacerdotales, el obispo atendía en primer lugar a las funciones sacramentales y litúrgicas de la catedral y, en segundo lugar, a las de las nuevas parroquias urbanas y rurales, erigidas estos siglos. Los delegados episcopales para atender las necesidades espirituales de la catedral serán en un principio los clérigos que con él vivían y servían la iglesia episcopal. Formaron grupos cada vez más estables y organizados, según constituciones episcopales y pontificias que irán configurando colegios canonicales de clérigos, con una norma de vida tomada generalmente del "Ordo monasterii", o con una norma de vida más secular, sin estar obligados a la vida en común ni a la pobreza.

A finales del siglo XII acaba configurado un grupo clerical sin vida común, pero manteniendo su personalidad jurídica y su mesa y rentas, separadas ya de la mesa episcopal. Este grupo, pues, había nacido del clero ayudante del obispo y que había desarrollado en su interior varias especializaciones referidas al culto en la catedral, función primordial para la que se funda el ya denominado cabildo catedralicio.

Así el cantor o chantre, el tesorero o sacristán y el deán, también llamado prior al comienzo en muchas iglesias, que debía ser presbítero y celebrar misa y los oficios en ausencia del obispo y presidía el grupo orgánico de los canónigos o capitulares. Otros oficios se habían desarrollado también por motivos sacramentales y sobre todo jurisdiccionales, como los arcedianos. Estos oficiales formaron el grupo de las dignidades o personas del cabildo catedralicio.

El resto de canónigos y posteriormente de racioneros se limitará, en principio, a mantener el servicio litúrgico de las Horas canónicas. El conjunto o cuerpo de canónigos y las demás personalidades y el deán, también mantendrán la administración litúrgica y de las rentas de las donaciones pro anima, que recibieron las catedrales en gran abundancia durante los siglos XII-XIV. Incluso, bajo la jurisdicción del obispo y con su aprobación expresa o tácita, el cabildo catedralicio podrá ordenar su vida interna y regular y controlar la conducta de sus miembros. El cabildo será en exclusiva el colegio electoral del nuevo obispo.

El poder episcopal de magisterio o de enseñar da nombre precisamente a la catedral, consiste en la predicación y la enseñanza del cristianismo al pueblo, con sus contenidos teológicos y morales, y además incluye el cuidado del desarrollo doctrinal y de los demás saberes que sirven para el avance de la teología y de su enseñanza, como la filosofía, el derecho, etc. Parte importante de este cuidado o vigilancia se manifiesta en el seguimiento de las corrientes heterodoxas y de las herejías, para combatirlas doctrinal y disciplinarmente.

El obispo puede conferir el oficio de la predicación a sus clérigos ayudantes. En primer lugar al maestrescuela, que desde el principio formó parte del cabildo catedralicio y también fue oficio, dignidad o persona. En las ciudades con 
universidad suelen ser los maestrescuelas o cancilleres, puestos por el obispo, los responsables del funcionamiento de la universidad, de los planes de estudio y del otorgamiento de grados a los estudiantes. Este maestrescuela y algún otro delegado puede, en nombre del obispo, controlar y desarrollar escuelas eclesiásticas oficiales, por ejemplo en algunas iglesias catedrales o colegiales, 0 escuelas privadas.

También el obispo suele conferir el oficio de la predicación y catequesis a los clérigos con cura de almas en las iglesias urbanas y rurales. Igualmente a predicadores pertenecientes a las órdenes mendicantes, a algún monasterio o al simple clero secular, que obtienen permisos episcopales para el desempeño de esta función.

También la confección de catecismos y la enseñanza de los mismos a niños y adultos forman parte importante de esta función magisterial, que el obispo suele encargar a los curas y sacristanes de parroquias. Esta actividad va enriqueciéndose e incrementando su importancia a partir del siglo XII, con los desarrollos de los catecismos y de sus contenidos y pedagogía.

El poder de jurisdicción tiene aspectos más discrecionales y consensuales con respecto a la sociedad en la que está cada iglesia episcopal. Sus elementos estructurales y algunos de sus desarrollos importantes aparecen en el Derecho Canónico que rige en toda la Iglesia Medieval. Las consecuencias del ejercicio de este poder fueron muchas en todos los campos, también en los momentos de enfrentamiento entre las justicias eclesiástica y temporal.

La primera consecuencia es la aparición y desarrollo de una geografía eclesiástica, principalmente la diocesana, donde ejercer la jurisdicción territorialmente, que afecta a todos los cristianos que viven dentro de sus límites geográficos. Principalmente, durante los siglos X-XIII, se establecen en toda Europa y también en España las diócesis territoriales, lo cual da lugar a bastantes litigios sobre límites con otras diócesis y eventualmente con los territorios e iglesias pertenecientes a los grandes monasterios antiguos, que pretenden ser exentos de la jurisdicción episcopal o al menos seguir ejerciendo sus antiguos derechos económicos sobre los habitantes de sus señoríos.

Esta proyección territorial de la jurisdicción episcopal hizo que las jurisdicciones personales en el interior de cada diócesis quedaran muy reducidas y sobre todo operó la aparición de subdivisiones regionales y parroquiales, fundamentales para la atención espiritual de todos los cristianos y para la ordenación y la percepción de los diezmos eclesiásticos. En este último asunto el poder episcopal era delegado de forma institucional y continua.

Parte importante de la jurisdicción episcopal fue el otorgamiento de normas y constituciones episcopales, en aplicación de sus poderes sacramental y magisterial, por ejemplo en los sínodos diocesanos y el otorgamiento de sus constituciones. Igualmente la aprobación de grupos o institutos clericales o laicos dentro de la diócesis, como beaterios, emparedamientos, hospitales, cofradías, etc. Las normas administrativas, que unas solían conformar los llamados cuadernos aplicables a toda la organización decimal del obispado, y otras solían contemplar también la forma de administrar las fábricas de las iglesias, las rentas de los hospitales, etc.

Junto a lo anterior estaba la audiencia o tribunal o consistorio episcopal, pues la justicia se hacía de forma directa por el obispo mismo, pero sobre todo de forma delegada. Unas veces mediante jueces y consistorios institucionales, como los del deán y eventualmente los de los arcedianos en su territorio jurisdiccional, o los 
tribunales decimales, que solían estar presididos por vicarios territoriales. Otras veces mediante jueces delegados directamente por el obispo a título personal.

Para el desarrollo de la justicia episcopal y de su aplicación, el obispo tenía una serie de servidores, clérigos y laicos, que atendían a los tribunales y a la ejecución de las penas impuestas. La mayoría eran espirituales, pero también las había pecuniarias. Podían ser de cárcel, ingresando clérigos o laicos en el calabozo episcopal, que solía estar en un palacio o en un castillo del obispo cuidado por los carceleros y los alcaides episcopales.

El obispo en su obispado ejercía además otras funciones laicas, como el señorío que veremos después, mediante la curia y la "casa" ${ }^{2}$ episcopales, es decir, mediante una serie de servidores directos de todas las categorías entre los clérigos y los laicos, que atendían directamente las órdenes del obispo. La curia era una institución dependiente inmediatamente del obispo, mientras que el cabildo catedralicio o las parroquias, por ejemplo, eran instituciones que dependían mediatamente del obispo. Sin embargo, la "casa episcopal" no era una institución religiosa sino meramente civil. Naturalmente, los servidores de su "casa" eran pagados generalmente de las rentas episcopales, pero también, especialmente los clérigos, lo eran de los beneficios eclesiásticos instituidos, de los cuales el obispo era colador ordinario y sobre muchos de ellos tenía poderes para designar al beneficiario.

La jurisdicción episcopal se extendía a todos los asuntos que por razón de la persona o de la materia eran tenidos entonces por propios del poder espiritual. Por razón de la persona, fundamentalmente, lo eran todas las causas de los clérigos o mixtas, que afectasen a un clérigo y a un laico. Por razón de la materia, todas las causas que afectaban a los sacramentos, como el Matrimonio y al divorcio, matrimonios dobles, etc., a los enterramientos, testamentos por razón de la donación pro anima, cementerio, etc., templos y sus pertenencias, derechos y rentas eclesiásticos, principalmente los derechos decimales y propiedades eclesiásticas, etc.

Naturalmente, la jurisdicción episcopal podía extenderse a través de muchos de los asuntos planteados a cuestiones, que la justicia civil podía entender como propias. Por ello, sobre todo las justicias concejiles y algunas de grandes señores, mantuvieron pleitos y enfrentamientos a veces violentos en la defensa de sus derechos jurisdiccionales señoriales o concejiles. Esto aún resultó más enrevesado porque los obispos mantuvieron una jurisdicción delegada de los reyes sobre los señoríos recibidos de ellos. Los señores laicos, incluidos los señoríos colectivos, que eran los concejos de realengo, en muchos aspectos, vieron en los obispos a sus competidores, pues ambos recibieron los señoríos y la jurisdicción del rey, sin pararse a distinguir entre asuntos espirituales y temporales.

PROYECCIÓN SOCIAL DEL OBISPO-SEÑOR.

Con esto hemos adelantado un último punto sobre las funciones del obispo en la Edad Media, que corresponde más a su proyección social que no a su institución

${ }^{2}$ La curia y la casa de los obispos medievales han sido poco estudiadas en España. Puede adquirirse alguna idea en Sanz Sancho, I. 2005 . "Notas sobre la casa de los obispos de Córdoba en la Edad Media". Espacio, Tiempo y Forma. Revista de la Facultad de Geografía e Historia. Serie III, 18. Historia Medieval, UNED: 245-264. 
eclesial. El obispo también ejerció el papel de señor, con su administración civil de un territorio y obligaciones militares consecuentes a la donación del rey.

En primer lugar, esta función asociaba aún más al obispo con la monarquía, de manera que el rey tenía interés en la designación de un obispo de su conveniencia y el obispo se beneficiaba de mantener buenas relaciones con el rey. Se unían, de un lado, el desarrollo de la reflexión política a favor de la monarquía, que ejercía la Iglesia mediante su episcopado. Los obispos tenían relaciones personales y eventuales lazos de dependencia con el rey, pues sin su favor era muy difícil hacer carrera eclesiástica.

En efecto, con las excepciones debidas, particularmente de los miembros de órdenes mendicantes, que ocuparon sedes pobres, como la de Cádiz, los obispos eran elegidos entre las aristocracias y las noblezas urbanas medias y grandes. Del mismo modo que los hijos de los grandes solían criarse y educarse en la corte del rey, los clérigos jóvenes provenientes de las grandes familias participaban de la capilla real y muchas veces formarán parte del consejo real. Mediante estos clérigos, que solían copar las dignidades de los cabildos catedralicios, el rey controlaba las actuaciones de los obispos y sobre todo la elección de los mismos, siendo aquellos los que más comúnmente eran elegidos por sus compañeros para obispo de la ciudad.

En segundo lugar, la función señorial del obispo hacía que mantuviera relaciones al mismo o parecido nivel de la aristocracia y de la nobleza con los poseedores de señoríos, incluidos los concejos de realengo.

En tercer lugar, la asunción plena de esta función señorial influyó bastante en aspectos intraeclesiales, como el ceremonial de la Confirmación o algunos ritos del sacramento del Orden, y mucho más en los aspectos externos del ejercicio del episcopado. Así, el cachete que proporciona el obispo al confirmando repite el rito del espaldarazo en la creación de caballeros. Igualmente, la promesa de obediencia y reverencia que hace el recién ordenado de presbítero entre las manos del obispo, repite el gesto de vasallaje del noble con relación al señor superior que le inviste con un feudo. Algo similar es la entrega de los objetos de su oficio a los ordenados de órdenes menores: las llaves a los porteros, las vinajeras y velas a los acólitos, los libros a los lectores.

La curia y la "casa" del obispo se constituían a imitación de la curia y de la casa del rey. Lo mismo sucedía con los demás grandes señores de finales de la Edad Media y en la Edad Moderna. Pero en el caso de los obispos las dos instituciones eran más antiguas.

La curia procedía de la audiencia episcopal y de la costumbre de escuchar a los consejeros antes de tomar una decisión. La casa era incluso anterior, pues el mismo San Pablo, como ya advertimos, condicionaba la promoción al episcopado a varias virtudes, entre otras la buena administración de su casa. En los tiempos medievales la casa del obispo estaba compuesta fundamentalmente por clérigos, la mayoría de los cuales habían estudiado o estaban en las universidades, y ejercían de capellanes, secretarios, abogados, fiscales, notarios, escribanos, jueces delegados en el consistorio episcopal, mayordomos, y canónigos en el cabildo catedralicio, etc. Otros servidores domésticos eran los médicos, cirujanos, barberos, panaderos, cocineros, aposentadores, pajes, etc. Como casa de un auténtico señor, tenía el servicio de caballeros, escuderos, carceleros, tenientes de castillos, alcaldes, alcaides, etc. 
La apariencia externa del obispo y muchas de sus manifestaciones eran plenamente señoriales, por más que en su ideal personal de virtud fuera humilde o mantuviera ritos tan pacíficos como la entrada como obispo de la ciudad sobre una mula, a imitación de la entrada de Jesús en Jerusalén.

Cuando a finales de la Edad Media los aspectos militar y administrativo del señorío episcopal se redujeron, la figura y la proyección social del obispo giraron hacia la del hombre letrado, que después dará la figura del humanista. En esto se juntan dos corrientes. Una tradicional, del obispo letrado para ejercer de juez y maestro de la fe y vigilante de todos los saberes que se enseñaban. Otra, en la que también estuvieron los nobles, dedicarse a la pluma y el libro y a la espada. En cualquier caso, el señor obispo fue desde el siglo XV más señor por ser cortesano y trabajar con la monarquía en su audiencia y chancillería, que por cabalgar al frente de ningún ejército, aunque la Iglesia siguiera respaldando obras de conquista o de defensa militar de la Cristiandad.

LAS FUNCIONES RELIGIOSAS Y ECLESIALES DEL OBISPO: PRESIDENCIA DE PONTIFICALES, DE PROCESIONES Y DE SÍNODOS DIOCESANOS.

Del obispo y su iglesia, la catedral, emanan todas sus acciones eclesiales. Las ejerce mediante normas y por el ejemplo. Así dice una constitución sinodal de la iglesia de Cartagena-Murcia:

"Commo sea cosa covenible que los miembros de la cabeça non se devan partir, antes es rrason e guisado e en todo e por todo la deven seguir. Por ende, commo la iglesia de Cartagena sea cabeça e madre de todas las yglesias de su obispado, rrason es mas en aquellas cosas que acuerdan con el derecho común e enforman buenas costumbres e la vida non solamente de los clérigos, mas de los legos. Regla pues que todas las otras yglesias que son en su obispado e rrepresentan un cuerpo con aquella, que non sean judgados por diversas constituciones e derechos. $E$ pues que la iglesia de Cartagena a rreçevido con rreverençia las costituçiones e leyes estableçidas e promulgadas por el honrrado padre e señor don fray Guillem obispo de Sabina ... Bien es derucherera rrason, que todas las otras yglesias del dicho obispado las deven rresçebyr e guardar e seguir en todas cosas la iglesia maternal...". 3

La catedral y sus alrededores son el escenario en donde aparece el obispo como fuente y cabeza de la iglesia local. Un ejemplo son las celebraciones pontificales, presididas por el obispo mismo, rodeado de todos sus clérigos y acompañado por la aristocracia urbana y el pueblo fiel, más las corporaciones religiosas, como las cofradías con sus estandartes y otras entidades parecidas.

${ }^{3}$ Sanz Sancho, I. 2002. Constituciones Sinodales de la Diócesis de Cartagena de 1323 a 1409. Edición y estudio, Ed. Universidad de Murcia. Fuentes Históricas de la Región de Murcia: 70. La llamada a la unidad de todas las iglesias murcianas, contenida en esta constitución sinodal, es mucho más que una simple repetición de principios o un convencionalismo. Todo lo contrario, sabiendo que está fechada en 1323 y que en 1304 el rey Jaime II de Aragón acabó por arrebatar al castellano reino de Murcia el territorio de la actual provincia de Alicante, que se constituyó en la Gobernación de Orihuela en 1366. Desde la cesión de esta parte del reino murciano a la Corona de Aragón, esta nueva entidad buscó continuamente su separación de la iglesia de Cartagena-Murcia, promoviendo su ascenso a diócesis, que consiguió ya en la Edad Moderna (1564), a fin de doblar en el plano eclesiástico la separación que ya se había producido en el político. 
Entre estas celebraciones hay que subrayar la más antigua y tradicional del Domingo de Ramos, a cuya procesión estaban obligados a asistir los miembros del cabildo catedralicio y los clérigos de la catedral, así como los clérigos de las parroquias. En Córdoba estos acudían con sus cruces procesionales, según una constitución del legado pontificio de 1246, sancionando una práctica anterior.

Otra procesión también muy importante fue la del Corpus Christi, a la que debían acudir las autoridades concejiles, las cofradías y los oficios con sus estandartes e insignias respectivas, corporaciones religiosas y el pueblo fiel. En estas manifestaciones religiosas brillaba la presidencia del obispo sobre una iglesia local diversa y jerarquizada.

Otra manifestación del estatus socio-religioso del obispo fueron las procesiones de recepción a los reyes en cada ciudad, encabezando la procesión con la cruz alzada de su iglesia diocesana.

El papel capital del obispo en su iglesia diocesana se ejerce en la celebración de sínodos y el otorgamiento de constituciones sinodales. Así vemos el comienzo de las constituciones sinodales promulgadas por el obispo de Cartagena-Murcia en 1370:

"Viernes, diez días de mayo, era de mil e quatroçientos e ocho annos, este dia en la çibdad de Murçia el honrado padre sennor don Nicolas, por la graçia de Dios e de la santa iglesia de Roma obispo de Cartajena, seyendo ayuntado con el cabildo de la dicha iglesia e con los clérigos parrochiales e capellanes de la dicha çibdad de Murçia, e con los arciprestes e vicarios, rrectores, clérigos, capellanes del dicho obispado, e con sus procuradores en esta santa signado, que el dia de oy çelebro dentro en la iglesia de santa María, do es acostunbrado, fiso e ordeno, con voluntad e otorgamiento de los sobredichos, estas costituçiones de la manera que siguen" ${ }^{\text {. }}$.

Por fin, el obispo, esta institución fundamental y fuente de toda actividad religiosa en la iglesia diocesana, con sus ayudantes directos en su curia y en su casa dio lugar a la construcción del palacio episcopal próximo, cuando no unido, a la catedral misma.

La catedral como tal quedó prácticamente exenta de la mayoría de las funciones, salvo las estrictamente litúrgicas, afectando sólo a algunas dependencias para guardar los libros y los objetos y las ropas del culto.

Las casas de los canónigos y de otros servidores de la catedral se mantuvieron en las proximidades, formando como un barrio, en el cual, mezcladas con otras casas de comerciantes, artesanos, labradores o caballeros, se extendían las casas del deán, del maestrescuela, de los arcedianos, de los canónigos, etc., que dieron nombres a calles en el casco antiguo de algunas ciudades, varios de los cuales aún se mantienen. Por el contrario, las dependencias para atender a los peregrinos, a los pobres y a los enfermos se ubicaron en otros edificios a veces cercanos, pero sin formar parte de la estructura arquitectónica de la catedral.

\footnotetext{
${ }^{4}$ Sanz Sancho, I. Ibidem: 94.
} 